\title{
SpeakApps 2: Speaking practice in a foreign language through ICT tools
}

\author{
Christine Appel ${ }^{1}$, Mairéad Nic Giolla Mhichíl², Sake Jager ${ }^{3}$, \\ and Adriana Prizel-Kania ${ }^{4}$
}

\begin{abstract}
SpeakApps 2 is a project with support of the Lifelong Learning Programme, Accompanying Measures. It follows up on the work and results reached during the KA2 project "SpeakApps: Oral production and interaction in a foreign language through ICT tools". The overarching aim of SpeakApps 2 is to further enhance Europeans' language learning skills through both self-directed learning and purposeful, teacher-designed materials that can leverage an evergrowing body of Open Educational Resources (OER). SpeakApps 2 targets not only HE educators and teacher trainers, but also those in VET and Secondary Education, and aims to widen the pool of resources for building language teaching skills via scalable trans-European collaborations and innovation using ICT and mobile technologies. SpeakApps 2 now takes further steps to diffuse the results in new countries and to synchronize efforts in European language teaching, in particular using OER. To achieve this, SpeakApps 2 has the objectives of a) integrating five new languages and including new education sectors, and b) developing a scalable digital framework able to bring in more languages, while spreading SpeakApps 2's methodologies and mobile solutions through a series of workshops, targeting the interests of open source communities and other projects for the sharing of resources and future innovations.
\end{abstract}

Keywords: speaking skills, OERs, tandem, teacher training, KA2 languages.

1. Universitat Oberta de Catalunya, Barcelona, Spain; mappel@uoc.edu.

2. Dublin City University, Dublin, Ireland; mairead.nicgiollamhichil@dcu.ie.

3. Rijksuniversiteit Groningen, Groningen, Netherlands; s.jager@rug.nl.

4. Uniwersytet Jagielloński w Krakowie, Krakow, Poland; prizelkania@gmail.com.

How to cite this article: Appel, C., Nic Giolla Mhichíl, M., Jager, S., \& Prizel-Kania, A. (2014). SpeakApps 2: Speaking practice in a foreign language through ICT tools. In S. Jager, L. Bradley, E. J. Meima, \& S. Thouësny (Eds), CALL Design: Principles and Practice; Proceedings of the 2014 EUROCALL Conference, Groningen, The Netherlands (pp. 12-17). Dublin: Research-publishing.net. doi:10.14705/rpnet.2014.000187 


\section{Introduction}

A needs-analysis study conducted at the beginning of the project in 2011 (available from the project website http://www.speakapps.eu) confirmed that the teaching and learning of oral skills is one of the greatest challenges faced by language learners and teachers, especially in foreign language classrooms. With the internet, access to authentic oral texts in the L2 is becoming less problematic, but for learners, opportunities for guided production and interaction in the $\mathrm{L} 2$ are still difficult to come by. There is too little time in the traditional or blended classroom, particularly if the class size is large.

In addition, even when learners manage to speak, given the ephemeral nature of speech, it is difficult for teachers to give learners adequate feedback. If all of the students speak in small groups, the teacher cannot possibly listen to all of them, much less provide feedback, and students are more likely to lapse into their native languages or wander from the task. If only a few students speak, the rest of the class is silent and wastes the precious little time they have to speak; although the teacher can listen and provide oral feedback on the spot in such a situation, learners often do not benefit from this feedback unless they have an opportunity to interact and to produce an output (Gass, Mackey, \& Ross-Feldman, 2005). A recording provides an opportunity for those students who have interacted with the teacher to review feedback and indeed if appropriate to produce further oral output.

In distance learning, there are acknowledged barriers for learners to communicate with one another (Berge, 2013). Although they can speak with one another synchronously via applications such as Skype and even record themselves if they purchase appropriate software, recordings must often be delivered to the teacher separately and it is difficult for the teacher to monitor what the students have actually done. In this context opportunities for peer-feedback are also missed.

\section{Method}

\subsection{SpeakApps tools}

The SpeakApps project began at the Universitat Oberta de Catalunya (Open University of Catalonia, hereafter "UOC") to address the need for a means by which learners could engage in L2 production and interaction in a completely online environment. The priority was to develop open-source tools complying with Learning Tools Interoperability (LTI) (http://www.imsglobal.org/tools interoperability2.cfm) standards in order to make the integration of the tools into 
different learning management systems (LMS) or other virtual spaces easy and transparent to the users.

Several tools were developed to meet these needs, and over the years through collaboration with SpeakApps partners and piloting in different institutions and contexts, the following four tools are the result.

\subsubsection{Langblog}

Langblog provides a blog in which teachers and learners can make audio and video contributions from a web browser without the need to install any additional programmes. It was designed with asynchronous oral production in mind, and facilitating peer-feedback was a priority in its design. It has the additional advantage of being secure, such as being open only to participants in a course, thanks to its LTI specifications which allow the tools to inherit the existing user permissions information in the virtual classroom. This is an important feature for primary and secondary educational sectors, but also for language teachers and students in general.

\subsubsection{Tandem}

Essentially an activity manager, Tandem delivers materials to pairs of learners in real time and shows teachers' temporal statistics. It is designed to be used with Videochat but can be used with any synchronous communication application (e.g. Skype). The Tandem tool allows students to engage in information-gap activities and role-plays outside the classroom and without the intervention of the teacher, who can then access the recording of the conversation at a later stage in order to give feedback to the students. Teachers and instructional designers have access to activity logs providing information on how students proceeded from one activity to the other, which has allowed for continuous improvement of the activities.

\subsubsection{Videochat}

Videochat provides up to six participants with an online application for videoconferencing and recording. There is no need to download anything for it to work or to export or send recordings -all features are integrated in the tool itself. In this way, learners can work independently, setting up sessions, recording conversations and archiving them in the virtual classroom without the need for teacher intervention. 


\subsubsection{The SpeakApps OER}

The SpeakApps Open Educational Resources is an x-wiki-based repository for oral activities that is open to the global community. In addition to acting as a library for oral activities, it also serves as an authoring tool for the creation of Tandem tasks. The OER is searchable by language, CEFR level, resource type, as well as task type, and users are invited to tag activities as well as leave comments on those created by others. Tasks can also be downloaded in pdf format.

\subsection{Use of the tools}

At the Universitat Oberta de Catalunya (Barcelona), Langblog has been used in foreign language classrooms for the past five years, and Tandem for the past three, by approximately 8,000 learners per semester. The tools have also been used extensively at the University of Groningen (The Netherlands), Dublin City University (Ireland), Jagiellonian University (Krakow, Poland), and the University of Jyväskylä (Finland), all members of the SpeakApps project, as well as dozens of other institutions in more than 100 pilots around the world.

In line with the exploitation and sustainability plan laid out in the first phase of the project (2011-2012), the SpeakApps tools are now entering the post-development phase, in which SpeakApps offers paid service packages for installation and maintenance of the tools. The tools themselves are open source, and therefore can be downloaded from Sourceforge (http://sourceforge.net/) and used by anyone for free. The service is offered for those who lack the necessary technological infrastructure or who prefer to contract such a service.

There are essentially three modes of use available:

- Institutions install the open-source SpeakApps tools in their own ICT infrastructure, which requires video-conferencing licenses and an LMS. Such institutions can enter into development collaboration with the project.

- Institutions contract the UOC to provide a full Moodle platform with the SpeakApps tools installed. The UOC hosts these services in the cloud.

- Institutions contract the UOC to integrate the tools into their own LMS. The integration is transparent and is maintained in the SpeakApps cloud service. 


\section{Discussion}

The project is continuing to grow and develop mainly in four areas: target languages, teacher training, activities in the OER and developments of apps for the use of the tools from mobile devices.

In the first phase of the SpeakApps project (2011-2012), the principal languages were English plus those of the research partners: Catalan, Irish, Polish, Dutch and Swedish. The second phase of the project (2013-2014) has seen the expansion of this set of languages to include Spanish, French, Croatian, and Italian. Each of the tools has an interface in each of these languages, as well as a category for content in that language in the OER. The tools' user information manuals (http:// langblog.speakapps.org/speakappsinfo/) have also been translated into many of these languages. The interfaces of the tools in particular were designed to make crowd translation possible, and currently we are in discussion with users of the tools in Basque language education. Offers to translate the tool interfaces, manuals and pedagogical content into other languages are more than welcome from anyone interested in collaborating.

Thirty-six teacher training courses have been run in most of the project's languages, and free online training courses are regularly offered on the project's website (http://www.speakapps.eu/). These courses introduce teachers to teaching languages online, the use of the tools in such teaching, and about other matters such as feedback, grading, and task design and delivery. Several of the courses have been organized and run by teachers who have come to use the tools at their institutions, and the project is happy to provide support for such courses.

The SpeakApps OER has seen significant growth over the second phase of the project and shows every sign of continuing to do so in line with the growing body of SpeakApps users. In response to the project's own iterative approach to development and the contributions of users in this respect, new features, such as more robust search functionalities, have been introduced. Other new features such as rating systems and other means of quality assurance are in the planning stages and will be introduced as they are developed.

Mobile versions of Langblog and Videochat and a mobile-specific version of Tandem (which already works on many devices) are in production in response to multiple institutions' and users' demands. The project has reports of Tandem already in use in pair work in classrooms -learners view oral tasks on tablets in an effort to streamline logistics, to increase student motivation, not to mention save paper. 


\section{Conclusions}

The SpeakApps project has developed since its start in 2011 in line with technological and pedagogical innovations in the area of education and ICT. The need for more practice time in order to become fluent in a second/foreign language is going to continue to be key for language learners and the project aims to outlast the current solutions and be ready for flexible adaptation as new solutions become possible.

New lines of activity in the future include a MOOC which will be run on the SpeakApps platform in the fall of 2014 for Spanish native speakers learning English and English native speakers learning Spanish. This MOOC aims at equipping students with strategies to benefit from opportunities to converse online with native speakers of their target language. Although numerous such opportunities already exist in social networks devoted to language learning, findings in studies of these networks show that the sustainability of such activity is low in that participants do not stay long in these networks or report poor results in terms of language learning. In equipping students with strategies to maximize their learning, students will be able to take full advantage of their participation in oral tasks with native speakers, as well as prepare for B2 official examinations.

The project partners are currently looking to contact new partners for continuing work mainly in two directions: a) research on different aspects of the acquisition of oral skills in a foreign language online, in particular task design and e-feedback, and b) future development of the tools and platform to add features that will enhance and facilitate evaluation and feedback.

Acknowledgements. This project has been funded with support from the Lifelong Learning Programme of the European Commission. This paper reflects only the views of the authors, and the European Commission cannot be held responsible for any use which may be made of the information contained herein.

\section{References}

Berge, Z. L. (2013). Barriers to communication in distance education. Turkish Online Journal of Distance Education, 14(1), 374-388. Retrieved from http://tojde.anadolu.edu.tr/tojde50/pdf/ article_31.pdf

Gass, S. M., Mackey, A., \& Ross-Feldman, L. (2005). Task-based interactions in classroom and laboratory settings. Language and Learning, 55(4), 575-61. doi:10.1111/j.00238333.2005.00318.x 